\title{
ENTREVISTA: (DES)CAMINHOS CRÍTICOS UM OLHAR DA PESQUISADORA RITA TEREZINHA SCHMIDT SOBRE SEU PRÓPRIO TRABALHO
}

\author{
Rita Lenira de Freitas Bittencourt \\ Universidade Federal do Rio Grande do Sul, UFRGS, Porto Alegre, RS, Brasil
}

A professora titular da Universidade Federal do Rio Grande do Sul (UFRGS), Rita Terezinha Schmidt, premiada, em 2015, pela FAPERGS como Pesquisadora do Ano na área de Letras e Artes, tem uma larga experiência em docência e pesquisa e tornou-se uma referência, especialmente nos estudos literários voltados a questóes atuais que incluem as reflexóes críticas sobre gênero, trauma, pós-humanismo, ecocrítica, corporeidade e ética. Ela também participa do GT Mulher e Literatura da ANPOLL desde 1987, sendo uma das fundadoras, e já compôs diversas comissóes e comitês nacionais e internacionais. Atualmente é membro-eleito do Comitê de gênero, um dos comitês permanentes junto à diretoria da Associação Internacional de Literatura Comparada (ICLA). Tem orientado inúmeras dissertaçóes e teses e hoje boa parte de seus orientandos pertence ao quadro do ensino superior brasileiro.

Há diversas entrevistas suas, em periódicos nacionais e estrangeiros, que dáo conta dos aportes teóricos, da organização de eventos dentro e fora do espaço acadêmico e do resgate sistemático das escritoras e poetas brasileiras "esquecidas" pela historiografia, que já participam da história de sua carreira. Para além de tudo isso, a proposta desta entrevista é buscar um olhar da pesquisadora sobre ela mesma, seu trabalho, suas expectativas para o futuro e sobre sua inserção atual no espaço acadêmico transnacional.

\section{Como você percebe os efeitos do longo trabalho de resgate das escritoras brasileiras na cena literária atual? Há previsáo de uma publicação que sistematize os seus diversos percursos como pesquisadora?}

O trabalho de resgate de escritoras brasileiras do passado, a partir da constataçáo da invisibilidade de sua produção no cenário da historiografia e da crítica literária, constituiu um dos eixos de extensa pesquisa por parte de docentes pesquisadoras de várias instituiçóes de ensino superior localizadas em diversas regióes do país desde o final dos anos de 1980. Foi um trabalho coletivo gigantesco de descoberta em bibliotecas públicas 
e acervos particulares de obras com edições datadas do século XIX e cujo rastreamento foi possível graças ao Dicionário Bibliográfico Brasileiro do Sacramento Black, entre outros. A pesquisa resultou na edição dos três volumes de Escritoras brasileiras do século XIX pela Editora Mulheres, sob a coordenação da saudosa colega Zahidé L. Muzart. A partir de referências de fontes contidas nos capítulos dos referidos volumes, deu-se início ao trabalho de leitura crítica de textos esquecidos, o que propiciou muitas reflexões sobre a constituição do campo literário. No centro dessas reflexôes, emergiu a crítica aos paradigmas até pouco tempo não questionados entre nós, como, por exemplo, de tradição, de cânone, de valor, de história literária e de cultura letrada - paradigmas que atuaram como mecanismos de controle e de legitimação do que se definiu como Literatura e autoria. Penso que os efeitos positivos do resgate são relativos a cada contexto institucional. Quanto mais uma instituição se constituiu historicamente como centro de referência, do ponto de vista histórico e geográfico, mais reticência haverá com relação aos textos de autoria feminina e isso é muito visível nos currículos de ensino. Pode-se dizer, sem surpresa, que é das margens que vem a resistência à doxa da "alta literatura", definição que preserva o território da Literatura como sendo exclusivamente de autoria de homens. Hoje, o estudo de Literatura de autoria feminina através um sem número de dissertaçôes, teses e artigos críticos publicados pelo país afora coloca em crise a historiografia literária tradicional e sinaliza a urgência de uma nova história à luz de novos conhecimentos sobre o passado, de mudanças conceituais e disciplinares e de processos históricos e políticos. Do ponto de vista institucional, essa nova história ainda está por vir, pelo menos no contexto brasileiro. Minha colaboração para esse projeto, a par de reediçóes de algumas escritoras sul-rio-grandenses, girou em torno de discussóes sobre a tradição da cultura letrada e posições do pensamento crítico brasileiro sobre o cânone, sobre estética e sobre valor, além de explorara questão do nacionalismo e a formação da "comunidade imaginada" da nação. Alguns desses percursos são registrados na coletânea de ensaios Decentramentos/ convergências: ensaios de crítica feminista, que deve sair do prelo pela Editora da UFRGS ainda neste ano.

\section{A proposta de incluir na historiografia e nos currículos das Letras a produçáo literária feita por mulheres se cumpriu? A escrita feita por mulheres, hoje, está mais visível?}

Existe uma visibilidade significativa de textos de autoria feminina, 
seja no âmbito do GT da ANPOLL: A mulher na Literatura, que neste ano completa trinta anos, seja em termos de produçáo crítica sobre escritoras brasileiras contemporâneas, veiculada em artigos em periódicos, assim como nas programaçôes de congressos, seminários e encontros nacionais e regionais. Contudo, a readequação dos currículos de Letras em termos de inserção de textos de autoria feminina em programas de ensino ainda é tímida. Em alguns redutos acadêmicos, ainda há resistências no sentido de preservar o cânone a partir de uma definição de Literatura que exclui as mulheres enquanto sujeitos do discurso e da cultura. É necessário o reconhecimento institucional sobre a importância de um currículo cujo modelo possa incorporar o desenvolvimento das pesquisas acadêmicas em consonância com o desenvolvimento teórico. Não se trata de simplesmente incluir uma ou outra escritora em alguma disciplina já existente, mas sim de conceber, a partir de uma nova base epistemo-pedagógica, um currículo que possibilite releituras da tradição literária e de seu legado, e que possa levar ao entendimento dos campos de força da produção literária e crítica no contexto de relaçóes saber/poder que sustentaram e, em muitos contextos, ainda sustentam, uma forma de pensar excludente que sempre reivindicou para si a universalidade. Perguntas sobre como as mulheres são representadas nos textos, nos programas de ensino de Literatura, nas histórias literárias, que papel as escritoras (não)tiveram nas culturas nacionais, que legado nos deixaram, que significações estéticas e políticas estão inscritas nas figuras femininas presentes na chamada tradição literária podem subsidiar uma nova concepção de ensino de Literatura. No fundo, é uma questão sobre que tipo de formação se quer oferecer aos nossos alunos, futuros educadores em uma sociedade que ainda não resolveu muitos de seus impasses, dentre eles, o sentido de democracia e o respeito às diferenças, e as contradiçôes entre discurso e prática.

Quais são as escritoras mulheres do passado e do presente que você destacaria como textos literários relevantes tanto para o leitor leigo quanto para o pesquisador? Quais leituras ficcionais você indicaria?

Uma das precursoras foi Nísia Floresta, que reescreveu, em formato livre, o texto da escritora inglesa Mary Wollstonecraft intitulado Avindication of the rights of women, com o título de Direito das mulheres e injustiça dos homens (1832). Além disso, publicou um poema, no estilo épico, $A$ lágrima de um caeté (1848), o qual oferece um contraponto ao tratamento da temática indígena segundo a visão do romantismo nacionalista vigente na 
época. Duas ficcionistas merecem destaque nesse período, ambas com obras publicadas no ano de 1859: Ana Luiza Azevedo e Castro, cujo romance Dona Narcisa de Villar desvela as violências decorrentes da colonização portuguesa e da miscigenação, tais como o rapto de mulheres indígenas, violência sexual e a assombração do incesto, e Maria Firmina dos Reis, cuja obra, Úrsula, antecedendo em 16 anos o canônico A escrava Isaura, de Bernardo Guimarães, constitui um libelo contra a escravidão, na medida em que a narradora conceder voz a personagens negros que relatam episódios da escravidão, inclusive o horror da travessia do Atlântico e as diversas formas de violência a que foram submetidos em terras brasileiras. São romances que contrariam o clichê cultural, talvez ainda vigente, de que as mulheres escreveram romances sentimentais e pueris! A mais prolífica escritora brasileira entre os séculos XIX e o XX é, sem dúvida, Júlia Lopes de Almeida, com 11 romances publicados desde sua estreia, em 1888, com Memórias de Marta, no qual aborda, de maneira empática e solidária, o drama da vida em cortiço do Rio de Janeiro. Trata-se de um romance pioneiro, considerandose que $\mathbf{O}$ cortiço, de Aluízio de Azevedo, foi publicado dois anos depois, em 1890. Mas é o texto de Azevedo que foi canonizado. Aliás, muitas escritoras foram pioneiras: é o caso de Delfina Benigna da Cunha (1834), que inaugurou a poesia culta no Rio Grande do Sul, em 1832, com a obra Poesias oferecidas às senhoras rio-grandenses, e de Rita Barém de Melo (1868), cuja obra Sorrisos e prantos é um marco na produção da primeira geração romântica do estado. Segundo o historiador e crítico Guilhermino César, ela teria sido casemiriana antes de Casimiro de Abreu! Entre o final do século XIX e a primeira década do século XX, cabe mencionar: a ficção de Maria Benedita Bormann (1893) e seu pioneirismo no romance Celeste, evidente já no primeiro capítulo. Trata-se de uma cena de violência doméstica que se desenrola no quarto do casal seguida do rompimento da aliança conjugal com a saída de casa da personagem feminina, que inicia outra trajetória de vida; e o romance $\mathbf{O}$ Perdáo, de Andradina de Oliveira (1910), precursora do romance urbano no Rio Grande do Sul, ao contrário do que dizem os historiadores ao apontar a estreia do romance urbano na década de 20 com Dionélio Machado e Érico Veríssimo. A produção das escritoras brasileiras da primeira metade do século XX é considerável, mas seus textos ainda permanecem no limbo, basta dizer que, até os anos de 1980, apenas três receberam alguma atençáo de parte da crítica: Raquel de Queiroz, que foi aclamada pelo seu "estilo viril", Cecília Meireles e Clarice Lispector. Poderia destacar a importância da poesia de Gilka Machado e de Lila Ripoll, e de romances como Lutas do coraçáo, de Inês Sabino (1999), e Parque Industrial, de Patrícia Galvão (1933). Dentre os romances de 
escritoras contemporâneas, destaco, além de obras das gaúchas Lya Luft, Patrícia Bins e Tania Faillace, As meninas, de Lygia Fagundes Telles; Um defeito de cor, de Ana Maria Gonçalves; Becos da memória, de Conceição Evaristo; As doze cores do vermelho, de Helena Parente Cunha; O lugar escuro, de Heloisa Seixas; Sinfonia em branco, de Adriana Lisboa; e Uma duas, de Eliane Brum. Ainda há as poetas, como Adélia Prado e Hilda Hilst, entre tantas outras.

Comente os caminhos atuais dos estudos de gênero. Pode-se pensar uma pesquisa conjugada aos estudos culturais e às outras minorias? Que teóricas você destacaria como relevantes para quem se interessa por esse conceito de gênero?

Inicialmente, gostaria de dizer que acho preocupante a recente popularização da expressão "identidade de gênero" presente em várias falas, principalmente de mulheres, que a usam como bandeira de luta política pelo reconhecimento. Penso que a apropriaçáo do termo "gênero" dissociado de qualquer um de seus contextos teóricos tem favorecido a banalização de seu sentido - a redução da identidade pelo viés de uma única categoria imbricada na definição patriarcal de diferença sexual - que acaba ratificando, perigosamente, o fundamentalismo do pensamento binário que sempre congelou as identidades a partir de categorias fixas para melhor controlálas e também, estigmatizá-las. Dito isso, vou delinear alguns percursos do conceito. Quando, na década de 1980, surgiu o conceito de gênero, deslocado do seu uso linguístico para se tornar uma categoria de análise, foi saudado pelas feministas de dentro e de fora da academia como um divisor de águas nas áreas humanas. Para nós, da Literatura, a importância da categoria foi reconhecida pela constatação de que gênero sempre fora uma categoria determinante na produção, circulação e recepção do discurso literário na tradição patriarcal, sem falar na constituição do próprio campo, suas convençôes, suas tradiçóes e histórias. De um lado, o conceito, em seu caráter relacional, remete à diferença hierarquizada entre homens e mulheres presentes em redes de significados - social, cultural, histórico, psicológico, político - impostos sobre o sexo anatômico. Sua voltagem crítica serviu para colocar sob suspeita os discursos construídos a partir do ponto de vista de um genérico universal, responsável pela invisibilidade da mulher como sujeito no campo do conhecimento, da cultura e das artes ao longo da história. É nessa linha que se insere o trabalho pioneiro de Elaine Showalter (1977) em A literature of their own, um trabalho de ginocrítica que buscou resgatar 
a mulher como escritora na tradição da Literatura de Língua Inglesa. De outro lado, o conceito de gênero colocou em pauta uma questáo debatida no contexto das teorias feministas dos anos 1980 e 1990: como repensar a identidade/subjetividade feminina evitando práticas excludentes, falsamente universais, ou generalizaçóes essencialistas que poderiam redundar em um reposicionamento da mulher como uma diferença de menos em relaçáo ao sujeito normativo da cultura, o que seria falsearo potencial epistemológico e político da categoria? Os trabalhos de Joan Scott e de Teresa de Lauretis foram fundamentais na elaboraçáo do impacto e das complexidades do conceito. Scott comprovou o alcance da categoria de gênero na mudança de paradigma na produção de conhecimento histórico a partir de novos temas que forçaram um reexame crítico dos pressupostos reguladores da disciplina, dominada por historiadores. De Lauretis, por sua vez, elucidou o funcionamento do sistema sexo-gênero como construção sociocultural e um aparato semiótico que ela denominou "a tecnologia de gênero", problematizando o conceito raso de diferença pela via da biologia ou socialização para enfatizar os processos de significação e efeitos discursivos. Com isso, de Lauretis evitou recair na concepção da mulher como personificação de uma essência incorporada ou uma feminilidade metafísico-discursiva. Em termos gerais, os trânsitos do conceito de gênero enfocando a diferença hierarquizada entre homem e mulher inscritos em redes de significados impostos sobre o sexo anatômico perduraram por duas décadas. $\mathrm{O}$ trabalho de Judith Butler, no qual repercute influxos do pós-estruturalismo e do pensamento associado à desconstrução derridiana, foi pioneiro ao rejeitar a noção de que sexo e gênero poderiam ser vistos como noçóes distintas uma da outra, o primeiro se referindo à biologia e o segundo à cultura. Nesse sentido, Butler derrubou a força do argumento sobre a determinaçáo biológica abrindo um leque de interrogaçōes sobre identidades sexuadas e colocando em discussão a fixidez da definiçáo essencializada da diferença homem/mulher, masculino/ feminino como a única oposição a ser problematizada, uma vez reconhecida as dificuldades de se estabelecer fronteiras e significados fixos para toda e qualquer identidade humana sexuada. Os caminhos dos estudos de gênero tem se ampliado significativamente nas últimas três décadas ao conjugar gênero com outras categorias da diferença como raça, classe e etnia, levando em conta os contextos históricos diversificados de relaçóes de poder e opressão, e estabelecendo interfaces com a ecologia (ecofeminismo) e com os estudos de animais, sobretudo com foco no debate filosófico sobre o humano, o humanismo e o pós-humanismo. Eu diria que os estudos culturais nasceram sob o signo interdisciplinar, da mesma forma que as teorias feministas, mas esses dois campos não dialogam necessariamente entre si, até porque, no 
meu entendimento, os estudos culturais não procedem de uma posição crítico-política de intervenção em relação à dominaçáo, seja na produção de conhecimento, seja em relação aos processos no campo social e cultural.

\section{Como está a Universidade hoje? Houve avanços teóricos, nos estudos das Letras, em relaçáo ao cenário que você encontrou quando entrou?}

Eu me formei em Letras pela UFRGS em 1974, período da repressão militar e no auge do estruturalismo no país. Durante a graduação, na disciplina de Teoria da Literatura, lemos obras de Vitor Manuel de Aguiar e Silva, Georg Lukács e Lucien Goldman, bem como obras sobre personagem, tempo e espaço na narrativa via E. M. Forster, Tzvetan Todorov e A. A. Mendilow. Quando entrei como docente em 1981, não observei mudanças significativas nas disciplinas de teoria. Todavia, a partir de 1986, com a criação na UFRGS da Associaçáo Brasileira de Literatura Comparada (ABRALIC) e com a realização de seus sucessivos congressos e simpósios, nos quais circulavam intelectuais respeitados do país e do exterior, o campo da teoria ganhou um novo fôlego. É importante lembrar que o primeiro congresso da ABRALIC, em 1988, realizado na UFRGS, teve como tema Intertextualidade e Interdisciplinaridade, conceitos introduzidos em trabalhos sobre as relaçóes Literatura e Antropologia, Literatura e Psicanálise, bem como sobre as relaçóes entre Literatura e outras linguagens, como o cinema e a pintura. Também foram abordados os conceitos de liminaridade e hibridismo, num movimento de visível abertura para o estudo de outras literaturas, particularmente as Literaturas latino-americanas, com enfoques sobre diálogos entre obras, releituras dos nacionalismos literários e questionamentos da historiografia oficial. Dentre as presenças, cabe citar alguns nomes que sempre estiveram associados à teoria: Antonio Candido, Douwe Fokkema (Holanda), Eneida Maria de Souza, Walter Moser (Canadá), Haroldo de Campos, Lisa Block de Behar (Uruguai), Jean Fisette (França), Ana Pizarro (Chile), Henry H. Remak (USA), Maria Alzira Seixo (Portugal), Raúl Antelo, e a então presidente, Tania Franco Carvalhal. Fiz questáo de fazer esse breve relato porque se trata de um momento importante da história da ABRALIC e da nossa história do Instituto de Letras da UFRGS. No início, Tania Carvalhal era uma professora do Departamento de Linguística, Filologia e Teoria da Literatura que tinha um sonho, fundar a ABRALIC, "a menina de seus olhos", como brincávamos entáo. Ela me conduziu pelos caminhos do comparatismo e tive o privilégio de acompanhá-la em Veneza em setembro de 2005, no 
encontro comemorativo aos cinquenta anos de fundação da Associação Internacional de Literatura Comparada (ICLA), no mesmo lugar em que havia sido realizado o seu primeiro congresso. Foi em Veneza que ela tomou posse como Presidente da Associaçáo, sendo a primeira mulher e a primeira pessoa da América Latina a ocupar o cargo. E foi lá que ela, lastimavelmente, pronunciou seu derradeiro discurso. Penso que o legado do comparatismo responde, em larga medida, pelas inovaçóes e avanços no campo da Teoria da Literatura entre nós, uma vez que alimentou e deu um novo perfil às disciplinas de teoria, tanto no curso de graduação quanto no programa de pós-graduação, com a criação do mestrado e doutorado em Literatura comparada na década de 1990.

\section{Coloquei no título dessa entrevista a expressáo “(des)caminhos críticos”, pensando no caráter formador e ao mesmo tempo transgressor do seu trabalho. Você concorda com essa leitura?}

Acho que posso concordar com essa expressão, entendendo o termo "(des)caminhos" como uma forma de desvio em relaçáo a um caminho supostamente natural ou normal que eu deveria seguir. Eu era uma guria do interior, aluna do Colégio Sagrado Coração de Jesus, na cidade de Ijuí, destinada a fazer o curso normal e a ser professora de primeiro grau. Em razão de um incidente relacionado com a náo entrega de um bordado no final do último ano do que hoje se chama primeiro grau (porque eu ensaiava, com o aval das freiras, na banda da escola no período da disciplina chamada "trabalhos manuais" e náo fui avisada da avaliaçáo), fui impedida de me matricular. Com meus pais indignados sobre a posiçáo intransigente das freiras, me vi fora da escola do dia para a noite, deixando para trás minhas queridas colegas que me acompanhavam desde a pré-escola. Fiz a seleção em outra escola e cursei o chamado "clássico" com ênfase em Línguas e Literatura, o que me dirigiu para as Letras. Quando me tornei docente da UFRGS, fui lotada no Departamento de Línguas Modernas em razão do doutorado em Literatura Norte-Americana. Mas, como minha pesquisa foi sobre Zora Neale Hurston, uma escritora afro-americana da Renascença do Harlem e que havia sofrido muito preconceito, inclusive de parte dos intelectuais negros da época, trabalhei com questóes de gênero e raça e foi nesse período que cresceu meu interesse pela teoria, pelo feminismo e pela autoria feminina. Talvez pelas histórias de meus desvios com relação ao que era esperado de mim, nunca cheguei a respeitar a divisão departamental do Instituto de Letras por considerá-la contraproducente em relação aos 
meus interesses de pesquisa, para não dizer que continua sendo uma divisão anacrônica, implantada durante os anos da repressão militar. Minha decisão de dirigir meu trabalho de pesquisa para a Literatura brasileira e comparada, com trânsitos pela teoria e pelas literaturas estrangeiras, propiciou-me, ao longo dos anos, muitas experiências enriquecedoras e muitas aventuras intelectuais que compartilhei com alunos e alunas maravilhosos, muitos dos quais hoje são meus colegas, e com algumas colegas incríveis das Letras com quem tive e tenho o privilégio de conviver. Trilhei caminhos na contracorrente do já instituído por acreditar que a voltagem do conhecimento está na possibilidade de ultrapassar os processos de normalização/naturalização decorrentes de preconceitos e da vontade de impor uma verdade e assegurar um espaço de poder. Quando o conhecimento abre fronteiras para o novo, ele cumpre uma função crítica, que é libertadora e que acena para outro lugar. E a transgressão é inerente a esse movimento que busca alcançar o lado de lá. Para mim, o (des)caminho é o caminho que escolhi. É evidente que sempre notei alguns olhares de hostilidade, senão de reprovação, dirigidos a minha pessoa, mas isso faz parte das outras histórias dos bastidores da academia...

\section{E daqui para a frente? Quais serão seus (des)caminhos críticos?}

Trabalhei, nos últimos anos, com romances contemporâneos com foco em trauma, corpo e memória e descobri que há uma longa história de narrativas de trauma na ficção de autoria de mulheres de várias geografias - e que tratam da ausência materna, da virtude sob o risco de violência, do abuso moral e sexual, incluindo estupro. São romances assombrados que geralmente imbricam a história individual com uma história coletiva em contextos de guerra, colonização, limpeza étnica e governo militar. A perda ou ausência da figura materna precipita, via de regra, eventos terríveis cuja narrativização é perpassada por silêncios, incoerências, rupturas de sequências, fragmentação da voz narrativa na intercalação de pronomes eu/ela. Isto é, o trauma congela a memória em torno da uma falta que resiste à simbolização e os sintomas aparecem nas estratégias empregadas na narração. A figura materna assume forma espectral, criando o efeito de uma narração assombrada. Neste ano, iniciei outro caminho de pesquisa, bem mais desafiador por tratar de um tema tabu em torno do qual há muito silêncio. $\mathrm{O}$ meu interesse sobre violência materna na Literatura surgiu no ano passado, quando um chamado nas redes sociais conclamou as máes a enviarem textos sobre os prazeres e alegrias da maternidade. Quando surgiu 
um texto dizendo o contrário, foi apagado, tirado de circulação. Resolvi entáo explorar as figuras de violência materna na medida em que me levam a problematizar os fundamentos da instituição da maternidade constituída, particularmente na cultura ocidental, no campo de crenças religiosas que a inscrevem na esfera do sagrado e no campo dos valores morais que dáo sustentação às formas jurídicas modernas. Para tanto, concebi a tópica da maternidade pelo viés do conceito foucaultiano de dispositivo, isto é, um conjunto heterogêneo de discursos de natureza social, religiosa, cultural e jurídica, com o objetivo de explorar a voltagem crítica da figura textual. Assim, pretendo evitar o enfoque tradicional da perspectiva de causa e efeito no tratamento da violência NA Literatura para destacar questôes de agência e performatividade, da violência DA Literatura ao criar um efeito perturbador enquanto um lugar de subversão à Lei do Pai.

\section{O que você faz quando náo está lendo, escrevendo, estudando?}

Gosto de ficar em casa, onde três coisas me dão muito prazer: o jardim, a música e a minha dachhund chamada Kika. Sou jardineira, comecei o jardim do zero, planto, podo e cuido das plantas, que incluem um coqueiro e um cipreste dedo de deus. É um lugar para caminhar, pensar e se encantar diante do mistério da vida pulsante que se desenrola nesse lugar, desde os tico-ticos com seus ninhos, aos passeios de sabiás, bem-te-vis, joóes-debarro e pombas rolas que alimento diariamente, sem falar nas borboletas e enxames de abelhas que tomam de assalto às pequenas árvores como a mimosa e a murta em época de floração (e de muitos perfumes). Já salvei dois pequenos gambás de afogamento e recebi visitas de grandes lagartos que se movem pensativos e pesados, sem falar nas aranhas e até de uma cobra (que não foi morta, foi levada embora!). Sentir a natureza viva faz com que eu a respeite e me reconheça como parte dela, desse extraordinário esquema de criação e transformação da vida. A música é diferente, me transporta para outras dimensóes e é, dentre as artes, a mais perfeita. Concordo com Edgar Allan Poe que a definiu como a mais concreta (depende das notas de uma pauta musical) e a mais abstrata (os sons produzidos) das artes. Escutar a música por ela mesma, e náo apenas como música de fundo enquanto se faz alguma atividade, é uma forma de ter vislumbres de uma beleza que parece transcender a nossa condição terrena. A companhia da Kika, com seu afeto incondicional, me comove, e chego a pensar que a presença dela tem me tornado uma pessoa melhor, menos exigente, mais maleável e compreensiva, talvez mais humana. Para alguns, pode parecer uma contradição! Para além 
dessas três coisas, é claro que sempre é uma festa quando recebo meus dois filhos e minhas noras para um almoço e que é um prazer enorme receber as amigas e amigos para rodas de longas conversas e risadas enquanto compartilhamos um espumante ou um café! 